\title{
Using real options analysis to evaluate the impacts of climate change on water security
}

\author{
$\underline{\text { B. Davidson }}^{\mathrm{a}}$, H. Malano ${ }^{\mathrm{b}}$, B. George ${ }^{\mathrm{b}}$, B. Nawarathna ${ }^{\mathrm{b}}$ and D. Ryu ${ }^{\mathrm{b}}$ \\ ${ }^{a}$ Dept. of Agriculture and Food Systems, University of Melbourne, Parkville, VIC, 3010 \\ ${ }^{b}$ Dept. of Infrastructure Engineering, University of Melbourne, Parkville, VIC, 3010 \\ Email: b.davidson@unimelb.edu.au
}

\begin{abstract}
In this paper the applicability of using Real Options Analysis to understand and measure the impacts of strategies deployed to counter the effects of climate change in a river catchment, are explored. The advantages of Real Options Analysis over the traditional discounted cash flow approaches are detailed. In addition, two limitations of the approach (the problems associated with assessing the very long time periods involved in climate change and the lack of estimated probabilities with which to assess various options) are identified. In terms of assessing the long term impacts of climate change, it is suggested that the analysis should be split into three manageable time horizons of 30 years each. While the results of doing this are not strictly comparable with the current ideas of a discounted cash flow, they are internally logically consistent with a Real Options Analysis and as a consequence should afford policy makers with the opportunity of comparing strategies. With respect to the problem of not having an objective measurement of the probabilities of climate events occurring, it is believed that incorporating the output of a dynamically downscaled global climate model into the yield function of the analysis may prove beneficial. Thus, any uncertainty is internalised and can be simulated directly on the outputs. The method outlined in this paper will be applied to evaluate water security in the Krishna Basin in India.
\end{abstract}

Keywords: Real Options Analysis, Climate change, Krishna Basin 


\section{INTRODUCTION}

A number of challenging and potentially insurmountable problems exist in assessments of the economic impacts of climate change and of the strategies that are proposed to either adapt to it or to mitigate against it. In particular, the time horizons over which any analysis needs to be completed are immense. Processes such as discounting future benefits (using a rate based on the opportunity cost of capital) and comparing them to current costs would yield a result that would suggest that any strategy is most possibly not financially viable. In addition, the possibilities of the impacts of climate change are often specified in terms of uncertainties, rather than risks with some bounds on the probabilities involved. An example of these problems is evident in Stern's (2007) evaluation of the impacts of climate change. This evaluation can be criticised because he assumed that the impacts were certain (working on the basis that ... if this, then that ...) and evaluated the options with a very low discount factor of $1 \%$ per annum. The debate on the issue of the correct discount rate has centred on the time preference of money (and presented by Quiggin in http://johnquiggin.com/2007/02/23/discounting-the-future-yet-again/). The issue addressed in this paper are how do you value the worth of undertaking a set of actions to solve a problem in which the risks associated with both the outcomes and the problem are not known with any certainty, over very extensive periods of time?

Real Options Analysis is a method that has been suggested could be used to come terms with these problems. Real Options Analysis is a variant of Decision Analysis, where the sequential processes involved in undertaking an action are laid out in a decision tree and are then assessed. At the centre of any form of Decision Analysis is an understanding and ordering of the risks associated with undertaking the action in question. However, traditional Decision Analysis is quite static and does not allow for the assessment of new and as yet unknown information that may alter events. What Real Options Analysis does is allow operators to incorporate this new information as, and when, it becomes available. However, as it currently stands, Real Options Analysis cannot be used to resolve the long term valuation problems inherent in many economic assessments of climate change or the unknown probabilities question.

In this paper an approach is outlined in which an assessment of different strategies used to combat the effects of climate change on a catchment's water security could be undertaken, within a Real Options Analysis. In this approach it is proposed that the probabilities of impacts of different climate scenarios be determined from a dynamically downscaled General Circulation Model, which is used to form the basis of the risks assessed and the strategies employed in the analysis. By incorporating cost effectiveness into the analysis, in place of the more usual cost-benefit approach, the valuation problems may well be minimised, but cannot be entirely eliminated. However, by segregating the analysis into separate but manageable investment time horizons, it may be possible to make some sense of the actions required to deal with the problems of evaluating the long term impacts of climate change. It is envisaged that this approach will be used to assess the impacts of climate change on water security in the Krishna Basin in India.

\section{THE PROBLEM}

At the heart of the complexity problem surrounding climate change, is the uncertainty of both the impact and the solution. Uncertainty can be defined in many ways, yet in this paper an approach specified by Knight (1921) is used. He suggested that there was a difference between risk and uncertainty. Put simply, a risk is an uncertainty that has a probabalistic parameter attached to it, while an uncertainty is a risk the probability of whose occurrence has not been determined. A major problem with sorting out the impacts of climate change is that much of the debate centres on the uncertainty of the impacts and of the remedial measures, and not on the risks associated with an impact or with the remedial measures. In defence of those who promote the climate change debate and those who suggest the remedialmeasures, putting a probability parameter on an event that can occur well into the future is a difficult task.

From an economic perspective, introducing time into any analysis makes most problems more difficult. While it is possible to hypothesise and model an impact arising from climate change and the effects that a measure to mitigate it might have, (calculating the benefits, costs and net present values of each) the degree of confidence one could place on the results needs to be questioned. For instance, anything past a 40 year time horizon and the normal opportunity cost of capital discounting tools used by economists reduces any generated monetary stream to approximately zero. In the case of climate change, where a reasonable forecast is taken out over 100 years, the benefits from any current act are low and decreasing in 100 years time, while 
the present costs are high. To overcome this problem Stern (2007) used a very low discount rate of $1 \%$ per annum, based on the acceptable idea of the 'time preference of money', but such an approach does not provide investors with the knowledge of the best individual strategy to pursue in this situation.

Assessing strategies that allow humanity to mitigate or adapt to climate change are required, as the problem is a significant one. Climate change will require significant social investment over a long period of time to rectify. Tools need to be developed that can adequately evaluate the required investment.

\section{RELATING THE PROBLEM TO WATER RESOURCE MANAGEMENT}

The complexity of climate change is disorientating, with a solution (like the problem itself) that at times seems to be both senseless and often menacing. The problem is heightened in the management of water resources for a variety of reasons. With respect to the economic components, very little is known about the value of water in its various guises, see Young (2005), Haneman (2006 ) and Hellegers and Davidson (2010). In addition any measure (like the construction of a structure or the implementation of a watershed development) is likely to exist for an extensive period of time. As a consequence, calculations of the stream of net benefits and discounted cash flows derived from employing water are difficult to determine. The initial current costs of construction are likely to be high while the discounted future benefits are likely to be low. Once constructed, opportunities exist to adapt these measures, or even to abandon them, in light of the availability of new information or technology.

The problem that needs to be addressed is how can adequate planning be undertaken in these circumstances? Policy makers need to know that the actions they take to combat climate change are effective from both a technical and an economic perspective? While it is recognised that none of these things can be known with certainty, perhaps the degree of certainty with which they are known can be improved.

\section{THE APPROACH}

Real Options Analysis has been suggested (by Hertzler 2007) as a method that can be used to assess the impacts of measures designed to mitigate and adapt to climate change. One of the many problems with climate change would appear to be that it is a situation where decisions are required and yet uncertainty is great. In addition, irreversibility is an ever present danger while a degree of flexibility in the response to the problem is required, over very lengthy periods of time. Real Options Analysis is an extension of the general net present value approach to managing risk. In Real Options Analysis complex decision-making trees are constructed from real data and are manipulated to take account of new information becoming available, thus allowing decision-makers to adjust strategies in real time.

Real Options Analysis extends traditional studies of risk framework in two fundamental ways. First, flexibility is added by allowing the ability to change strategies over time. No longer are investment choices binary ('go' or 'no go') decisions. Decisions can be delayed, accelerated, or even abandoned in a Real Options Analysis, as new information becomes available. Second, market prices are used to determine real values in a Real Options Analysis (WSAA, 2008).

In undertaking a Real Options Analysis Borison (2005), Yang and Blyth (2007) and WSAA (2008) all suggest slight variations on a basic four stage procedure. This involves:

- Structuring the problem so that the key elements, measures, decisions and uncertainties are identified.

- Undertaking a baseline analysis in which an economic model of the problem is specified and the discounted cash flows are presented.

- Conducting sensitivity tests on the uncertainties thought to be inherent in the baseline analysis.

- Evaluating the flexibility and options strategies that could be employed using the baseline analysis.

WSAA (2008) argued that water problems are best assessed using a 'risk adjusted decision-tree method' that relies on dynamic programming to evaluate alternatives. Such an approach means that the choices facing a policymaker are explicitly specified in a decision tree, where each branch represents a different alternative and where the probability of an event occurring is ascribed to each branch of that tree. While private risks can be subjectively applied in the analysis, public risks need to be objectively measured. Water authorities tend to take a cost minimisation approach to most projects, something that is quite reasonable when a fixed level of service is what is needed from a new intervention. However, in Real Options Analysis the aim is usually to 
optimise wealth. This, it could be argued, is a better approach to take in the case of climate change assessments, as different levels of service can be assessed for optimality, along with the different ways of achieving it.

While the baseline analysis is usually a discounted cash flow model where optimisation is assumed, the approach could be used to discover differences in a hypothesised activities using some form of a simulation model. The analysis relies to a great degree on market prices and nonmarket valuation techniques as much as possible, as it is this factor that makes Real Option Analysis 'real'. While most Real Options Analysis have used discounted cash flow techniques to assess private investment decisions, these assessments are not dissimilar to those involving decisions on public investments, in which tools such as Benefit Cost and Cost Effectiveness analyses are used.

Conducting sensitivity tests is a necessary part of most economic assessments. The aim with these tests is to determine how sensitive the outcomes are to changes in key variables, such as the water demand, the costs of supply, climate change, commodity prices, etc. A sensitivity test allows analysts to concentrate their effort on the parts of the problem where the greatest changes are likely to occur. Consequently, a sensitivity test is the first step in assessing the risk of a project and can be used to formulate the risk parameters.

Where Real Options Analysis is truly unique is in its assessment of flexibility. Flexibility in investment choices is derived (in part) from the timing of an event. It not only involves issues such as different start times, accelerating or decelerating development times, mothballing or even abandoning projects, but also in the modularisation of different aspects of the project, refurbishment and even changing technology. In any analysis what flexibility provides for, is the ability to learn as time goes by, to incorporate new information as it becomes available and then to change strategies if a better one is found. Real Options Analysis provides information on the costs and benefits of delaying an innovation. Surely this flexibility needs to be critically evaluated if any strategies to combat the long-running problems of climate change are to be assessed realistically?

McClintock (2009) suggests that the approach offers the opportunity to manage risk associated with uncertain future payoffs or costs, by determining the optimal length of delay for an investment. A strategy to delay an investment means that potential profits over the period of waiting are forgone. Real Options Analysis balances this against the value of the potential losses if an adverse event occurs, once the investment has been made.

\section{THE LIMITATIONS AND SOME EXTENSIONS}

It should be noted that in applying a Real Options Analysis to strategies designed to combat climate change, a number of problems still exist. Two in particular are of concern: those associated with the very long term time horizons involved; and the lack of objective probabilities surrounding climate change. The purpose in this section is to seek some resolution to these problems and to suggest methods which can be used to extend the approach to account for them.

One way around the problem of the long time periods is to think of the planning horizon in discreet thirtyyear segments, where each segment is evaluated separately. So if some idea of the climate is modelled on the whole of the 21 st century, then the Real Options Analysis could be worked over the period to say 2030 in the first instance, then restarted from 2031 through to 2060 and then restarted again from 2061 through to the year 2100. In each of the time frames the first year in any of the three periods is year zero (i.e. the present, 2031 and 2061). These particular years would need to be explicitly stated in the decision tree and identified as key points where decisions need to be made. In other words, they become points upon which the flexibility component of the options analysis is conducted. The values of the three different periods (including generous salvage value provisions) could then be summed. While this would not provide an accurate value of any set of investment strategies in the current value terms, it could be used to compare different strategies, all exhibiting the same limitation. This approach to the problem is logically consistent with many current practices in discounted cash flow studies and Real Options Analyses. However, some care would be needed in reporting the findings, as the measures are different to what is commonly understood by a net present benefit. In reporting the results there would be three individual results, for the immediate, intermediate and long-term time horizons. What would be found is that an individual strategy might be ideal in one time period, but not in another. 
A more significant problem exists in the specification of the probabilities of events occurring and of how well the remedial measures actually work. While it is acceptable to assess the risks to a private asset in a subjective manner, public risks need to be evaluated objectively. In climate change studies on objectively assessed risks are rare. Many analysts talk in terms of subjective uncertainties. One way around this problem is, in the baseline scenario and throughout the analysis, to connect a suitably scaled down climate change model to help explain and adjust the yield function in the analysis. So, in the case of water resource management, the yield may well be the degree of water security achieved, which in turn is determined in part by changes hypothesised from a global climate model. It should be noted that this solution in no way solves the problem of determining the accuracy of any probability arising from a change in the climate. Rather, all it does is alter the responsibility for determining the accuracy of a prediction back to those who make the initial pronouncements about climate change. However, taking this approach does allow the evaluation of different climatic outcomes to occur, if the whole modelling effort is simulated rather than optimised. In doing so different climate outlooks can be directly assessed through the outputs of the system. This would raise the sensitivity tests from purely being some 'best guess at the extremes of a yield variable', into the prime driver of the analysis.

\section{LINKING THE ANALYSIS TO THE PROBLEM: THE CASE OF THE KRISHNA BASIN}

Most Real Options Analyses of water issues have been assessments of investment decisions that farmers (see McClintock 2009) or urban water authorities (see WSAA 2008) need to make. Simarly, Yang and Blyth (2007) put forward a method that could be used to assess climate uncertainty on investment in the energy sector, over a short 30 year planning horizon. None of these studies required an evaluation of an investment strategy over 100 years, something that would be the case in assessing the effects of climate change in the water sector. It is proposed to apply the techniques discussed above in an assessment of the impacts climate change may have on water security in the Krishna Basin in India. The purpose in this Section is to discuss how this might be undertaken.

The Krishna basin flows eastward from the Western Ghats, through the states of Karnataka Maharashtra and Andhra Pradesh, to the Bay of Bengal. The flow of the river is greatly affected by precipitation from the Indian monsoons and by a number of physical interventions that extract water for agricultural and urban use. Two conflicting investment strategies are currently in place; one where investment in controlling large scale surface supplies are optimised and the other where small-scale watershed developments are promoted.

To undertake a Real Options Analysis it is first necessary to structure the problem. To put the problem in perspective the decisions that need to be addressed are should policy makers:

- $\quad$ invest in watershed developments; or

- refurbish the existing surface water infrastructure; or

- $\quad$ some combination of the two; or

- do nothing.

It is assumed that the motivation for making a decision in this case is driven purely by climate change, which has massive degrees of uncertainty associated with it and the actions of which will play out over the next hundred years. Associated uncertainties, in addition to those of climate change, include the possibility of cost blowouts and changing returns to users. It needs to be emphasised that this is a public investment problem, not a private one. Hence, policymakers are concerned about maximising the welfare to their citizens and about the cost effectiveness of any action they might contemplate. The measures of concern are therefore the Cost Effectiveness ratio, the Net Benefits to society and the purely physical need to maintain water security to users.

To undertake this analysis it is necessary to establish the discount cash flow analysis over a 100 year planning horizon. In setting up a spreadsheet three simplifying assumptions can be made. First, general inflation will not distort the current substitution among inputs and outputs and as such does not need to be accounted for in the analysis. Second, the yields that are derived from using water from different sources do not differ over time. As a consequence ground water contamination is not considered. Third, that policymakers have a 30 to 40 year planning horizon, within which they can make minor adjustments with the time horizon, but between them they can undertake large changes in direction. While the establishment of the timeframe is purely arbitrary, this assumption is believed to be realistic, as it is the way in which planning occurs. In making this assumption the whole analysis restarts every 30 years (in 2031 and 2061) and each of the outputs (cost effectiveness, net benefits and water security) are reported three times, once for each 
planning horizon. While not strictly comparable between time periods, they are comparable across the different scenarios assessed.

In constructing the baseline analysis it is necessary to come to terms with the supply and demand for regulated water supplies, now and into the future. Demand can be assumed to grow in line with population and other demographic characteristics (like the drift to greater urban use). Its value can be calculated from existing estimates of the own price elasticity of demand for water, see Davidson, et al. (2009). Supply on the other hand comes from a hydrological model of the basin, one that has incorporated in it, a component that allows for climate change. The usual rules of disregarding sunk costs investments and accounting for the total cost of any proposed changes need to be adhered to.

Risk can be introduced first by conducting a sensitivity test. In this case the supply and demand parameters are adjusted by (say) $10 \%$ and the impact this has on the output metrics measured. What is of interest are the changes in the measures from the baseline scenario. These need to be reported as they reveal how sensitive the model is to different components and assumptions. One of the important outcomes from the sensitivity analysis is in determining the risks of different events occurring. In the first instance any factor that was found to be insensitive can be excluded from the decision analysis, as these factors are not going to influence policy makers' decisions. Then the scenarios that do change can be compared.

Finally, in terms of the options analysis, it is necessary to delay and advance different options. Critically, there is a need to adjust the climate model and simulate its effects on the output metrics. In addition, the arbitrary start and finish times of any proposed strategy can be assessed to determine the benefits or costs of delaying or accelerating an action. It is the range of results that are important to policy makers in this case, as these reveal the degree of flexibility they have to operate in.

\section{CONCLUSIONS}

In this paper the issue of how to assess the long term impacts of climate change was discussed. It was suggested that the best approach was to take a Real Options Analysis and extend that to account, first for the unknown probabilities associated with climate change (by adding a scaled-down regional climate model to explain changes in supply) and then to recalibrating the model every 30 years or so, to overcome the problems associated with discounting. The Krishna basin in India was used to explain aspects of this approach. In the near future the framework outlined in this paper will be populated with data to determine the costs and benefits of investing in the different measures that could be used to adapt to climate change in the basin.

\section{ACKNOWLEDGMENTS}

The authors acknowledge the Australian Centre for International Agricultural Research (ACIAR) for their financial support.

\section{REFERENCES}

Borison, A. (2005). "Real Options Analysis: Where Are the Emperor's Clothes?" Journal of Applied Corporate Finance, 17(2), pp. 17-31.

Davidson, B; P Hellegers and M Samad. (2009). "Assessing the Economic Impact of Redistributing Water within a Catchment: A Case Study of the Musi Catchment in the Krishna Basin in India," In IWMI Working Paper 139. Colombo: IWMI.

Hanemann, W.H. (2006). "The Economic Conception of Water," In Water Crisis: Myth or Reality?, ed. P. P. Rogers, M. R. Llamas and L. Martinez-Cortina. London: Taylor \& Francis plc.

Hellegers, P and B Davidson. (2010). "Determining the Disaggregated Economic Value of Irrigation Water in the Musi Sub-Basin in India." Agricultural Water Management, 97(6), pp. 933-38.

Hertzler, G. (2007). "Adapting to Climate Change and Manageing Climate Risks by Using Real Options." Australian Journal of Agricultural Research, 58, pp. 985-92.

Knight, F.H. (1921). Risk, Uncertainty and Profit. Washington, DC: Beard Books.

McClintock, A. 2009. "Investment in Irrigation Technology: An Application of Real Options Analysis," In 53rd Annual Conference of the Australian Agricultural and Resource Economics Society. Cairns. 
Davidson et al., Using real options analysis to evaluate the impacts of climate change on water security

Stern, N.H. (2007). The Economics of Climate Change: The Stern Review. Cambridge: Cambridge University Press.

WSAA. (2008). "Real Options and Urban Water Resource Planning in Australia," In Occasional Paper. Melbourne: Water Services Association of Australia.

Yang, M. and W. Blyth. (2007). "Modeling Investment Risks and Uncertainties with Real Options Approach," In International Energy Agency Working Paper. Citeseer.

Young, R.A. (2005). Determining the Economic Value of Water. Concepts and Methods. Washington D.C: Resources for the Future. 